\title{
Correlation of Depression with the Functional Profile of Elderly People Living in Homes for the Aged
}

\author{
Alexandre Gomes Sancho1,2, Ataiane de Lima Silva1, Leonela Ribeiro de Paula1, \\ João da Silva Rosa', Álvaro Camilo de Faria ${ }^{3}$, Simone Neves1, Daniel Heitti Zidde1, \\ Marcus Vinicius de Mello Pinto ${ }^{4}$, Aline Ronis Sampaio4, Miriam Viviane Baron ${ }^{5}$
}

${ }^{1}$ School of Health Sciences, Department of Physical Therapy at the University of Rio Grande (UNIGRANRIO), Duque de Caxias, RJ, Brazil

${ }^{2}$ Rehabilitation Sciences, Augusto Motta University Center (UNISUAM), Rio de Janeiro, RJ, Brazil

${ }^{3}$ Integrated Colleges of the Extreme South of Bahia (UNESULBAHIA), Eunápolis, BA, Brazil

${ }^{4}$ Celulare Institute, Petrópolis, Rio de Janeiro, Brazil

${ }^{5}$ Program in Medicine and Health Sciences of the Pontifical Catholic University of Rio Grande do Sul (PUC/RS),

Porto Alegre, RS, Brazil

Email: alexandresancho.fisio@gmail.com

How to cite this paper: Sancho, A.G., de Lima Silva, A., de Paula, L.R., da Silva Rosa, J., de Faria, Á.C., Neves, S., Zidde, D.H., de Mello Pinto, M.V., Sampaio, A.R. and Baron, M.V. (2021) Correlation of Depression with the Functional Profile of Elderly People Living in Homes for the Aged. Advances in Aging Research, 10, 59-70. https://doi.org/10.4236/aar.2021.103003

Received: May 10, 2021

Accepted: May 25, 2021

Published: May 28, 2021

Copyright $\odot 2021$ by author(s) and Scientific Research Publishing Inc. This work is licensed under the Creative Commons Attribution International License (CC BY 4.0).

http://creativecommons.org/licenses/by/4.0/

(c) (i) Open Access

\begin{abstract}
Introduction: Due to the growth of the elderly population, there is a notable lack of preparation among family members and society to face the challenges of this new reality, resulting in an increasing demand for homes for the aged (HA). It is necessary to understand how the impairment of physical health, mental health and the level of depression can affect the functional capacity of the institutionalized elderly who live in homes for the aged. Objective: To describe the correlation between depression and functionality of elderly people who live in homes for the aged. Method: A cross-sectional, descriptive study with 70 elderly people of both sexes, aged 60 years or older, who live in HA in the state of Rio de Janeiro. Result: It was verified that the female gender was predominant in the HA consulted. The majority of elderly live in HA voluntarily $48.6 \%$ and that $41.43 \%$ did not complete elementary school. The majority of the elderly $81.43 \%$ had the ability to perform basic activities of daily living and the elderly $52.86 \%$ had normal psychological pictures. The worsening of the depressive picture is associated with the worse functioning of elderly who live in HA $(p<0.02)$. Conclusion: Depression is a factor that is associated with the functional capacity of the institutionalized elderly. The worse the functional level of the institutionalized elderly, the greater the chances of presenting a depressive state.
\end{abstract}




\section{Keywords}

Elderly, Aging, Depression, Functionality, Homes for the Aged

\section{Introduction}

Aging refers to a dynamic, progressive and irreversible event related to biological, psychic and social factors in which they trigger structural, physiological and psychological changes as well as social changes in the individual, favoring the development of pathological processes [1].

According to Shumway-Cook and Woollacott (2013), there are two main theoretical lines that study aging: one of them considers the primary aspects related to genetic characteristics and the deterioration of the nervous system and the other the secondary ones, which evaluates the influence of the damages caused by environmental factors, such as radiation, pollution, lifestyle, among others [2].

Due to the growth of the elderly population, there is a notable lack of preparation among family and society members to endure the challenges of this new reality, resulting in the growing demand for the elderly in homes for the aged (HA). The HA is defined as residential, governmental and non-governmental institutions for the collective housing of persons aged 60 and over who may have family support or not [3].

An important aspect related to the institutionalized elderly person is depression, because in HA, the elderly are excluded from living with society and adopt a different lifestyle. This social isolation leads to loss of identity, self-esteem and freedom, solitude and often resulting in a depressive state [4].

The consequences of aging may be risk factors for depression in the elderly, in which the disease is found in $10 \%$ of people over 60 , according to the united nations of Brazil (2017) [5].

Wannmacher \& Lenita in 2017, describe that about $40 \%$ of elderly who living in HA have depression [6]. According to the Pan-American health organization (PAHO/WHO, 2018) lack of interest, sadness for long periods and the decline of energy to perform daily activities characterize depressive disorders. Loss of memory, decreased visual acuity, and difficulty in move around add to make older people over 85 years of age more vulnerable to be depressed [5].

Functionality is defined as the ability to manage one's life or take care of oneself and is the basis of the concept of health for the elderly as well as being the starting point in their evaluation [7] functionality is today the great paradigm of geriatrics and gerontology, because it is necessary to understand how the commitment of physical health, mental health, autonomy, social integration, family support and economic independence can affect the functional capacity of the elderly person who has a long [8] [9].

According to the National Institute of Statistics (2014), about 50\% of the pop- 
ulation, aged 65 or over, said they had difficulty or could not perform at least one of six daily activities (see, listen, walk, memory/concentration, take bath/dress up, understand/make yourself (understood). In this way, the increase in the prevalence of chronic diseases influences the functional status of the elderly, reducing autonomy and independence [8] [10].

Therefore, the present study aims to describe the correlation between depression and function of elderly people living in homes for the aged.

\section{Material and Methods}

A cross-sectional and descriptive study of a qualitative approach was carried out with 70 elderly of both sexes, 40 women and 30 men, aged 60 years or older, living in HA of the state of Rio de Janeiro.

The present study was approved in $27 / 11 / 2017$ by the ethics committee of Unigranrio University (CAAE: 56001116.70000.5646) and is in accordance with resolution 466/2012 and resolution 510/2016. The elderly and their caregivers received a detailed explanation of the evaluation objectives and procedures and signed the informed consent form (ICF) agreeing to voluntarily participate in the research.

The inclusion requirements that were adopted are: elderly of both sexes, aged 60 to 100 years, who did not present severe cognitive impairment $(<13)$ evaluated by the mini mental state examination (MMSE) [11] and who accepted to participate in the study. Elderly individuals who presented auditory alterations and severe cognitive impairment (according to the MMSE criteria) were excluded.

Data collection was carried out from february to april 2018. The visits were pre-scheduled with the heads of the institutions. Ninety interviews were conducted with a duration of approximately 20 minutes.

The sample was initially composed of 90 elderly people, and after the beginning of the collection, it was identified that 18 elderly people presented severe cognitive impairment, 1 elderly didn't agree to sign the term of free inquiry and 1 elderly had serious hearing alterations, so they were excluded from the sample.

Sociodemographic characterization and questions related to health conditions were carried out through the structured script in the form of interviews, prepared by the researchers. The script included the following independent variables: gender, age, length of institution stay, marital status, offspring, reason for institutionalization, receiving visits, chronic diseases, use of medications, self-perception of health, report of pain, falls in recent months, fear of falls and dispositive to aid of gait.

The functional capacity of the elderly to perform the activities of daily living (ADL) was evaluated through the Katz [12] index, which evaluates the capacity for six basic activities: bathing, dressing, going to the bathroom, transferring from chair to bed and vice versa, control sphincters and feed themselves.

Depressive states were evaluated through the geriatric depression scale (GDS) [13], which is composed of easy-to-understand questions and has a small varia- 
tion in the response possibilities (yes/no).

\section{Results}

The description of the general characteristics of the elderly can be observed in Table 1. It showed that there was a predominance of the female gender (57.1\%) in relation to the male gender $(42.9 \%)$. The mean age of the elderly was 74.8 years. It was observed that $41.43 \%$ did not complete elementary education, $22.86 \%$ had completed secondary education, $18.57 \%$ did not study, $10.0 \%$ had completed elementary education, 5.71\% had completed higher education and only $1.43 \%$ had incomplete elementary education. The average length of institution stay calculated in months was 55 months. Half of the elderly were widowers $50.0 \%, 24.3 \%$ were single, $20 \%$ were divorced and only $5.70 \%$ were married. The average number of children was 1.57 per person.

The conditions of these elderly people in LSIE were observed in Table 2, showing that $48.6 \%$ lived in long stay institutions of their own free will, and $54.3 \%$ received visits. The majority of the interviewees (64.3\%) said they did not present chronic diseases, reported using medication (65.7\%), said no to reports of pain $(71.4 \%)$ and use of gaiters (75\%), are afraid of falling (51.4\%) and when asked about their self-perception of health, they reported good health (74.3\%). Only $24.3 \%$ said they had suffered falls in recent months.

Table 1. Characteristics of LSIEs. identification info.

\begin{tabular}{|c|c|c|}
\hline & $\mathrm{N}(\%)$ & Media \pm Standart Devil \\
\hline \multicolumn{3}{|l|}{ Gender } \\
\hline Male & $30(42.9 \%)$ & - \\
\hline Female & $40(57.1 \%)$ & - \\
\hline \multicolumn{3}{|l|}{ Age (years) } \\
\hline & - & $74.8 \pm 9.28$ \\
\hline \multicolumn{3}{|l|}{ Schooling } \\
\hline Higher education & $4(5.71 \%)$ & - \\
\hline Middleeducation C & $16(22.86 \%)$ & - \\
\hline Middle education I & $1(1.43 \%)$ & - \\
\hline Elementary education C & $7(10.0 \%)$ & - \\
\hline Elementary education I & $29(41.43 \%)$ & - \\
\hline Without study & $13(18.57 \%)$ & - \\
\hline \multicolumn{3}{|l|}{ Lenght of stay (months) } \\
\hline & - & $55.1 \pm 50.6$ \\
\hline \multicolumn{3}{|l|}{ Marital Status } \\
\hline Single & $17(24.3 \%)$ & \\
\hline Married & $4(5.70 \%)$ & \\
\hline Divorced & $14(20 \%)$ & \\
\hline Widower & $35(50.0 \%)$ & \\
\hline \multicolumn{3}{|l|}{ Number of chldren } \\
\hline & - & $1.57 \pm 1.73$ \\
\hline
\end{tabular}


Table 2. Conditions of stay.

N (\%)

\begin{tabular}{|c|c|}
\hline & $\mathrm{N}(\%)$ \\
\hline \multicolumn{2}{|l|}{ Reason } \\
\hline \multicolumn{2}{|c|}{ Homeless $19(27.1 \%)$} \\
\hline \multicolumn{2}{|c|}{ Own will 34 (48.6\%) } \\
\hline \multicolumn{2}{|c|}{ Decision of Family 17 (24.3\%) } \\
\hline \multicolumn{2}{|l|}{ Recevies visits } \\
\hline No & $32(45.7 \%)$ \\
\hline Yes & $38(54.3 \%)$ \\
\hline \multicolumn{2}{|l|}{ Chronic diseases } \\
\hline No & $45(64.3 \%)$ \\
\hline Yes & $25(36.7 \%)$ \\
\hline \multicolumn{2}{|l|}{ Use of medicines } \\
\hline No & $24(34.3 \%)$ \\
\hline Yes & $46(65.7 \%)$ \\
\hline \multicolumn{2}{|c|}{ Self-perception of health } \\
\hline Poor prognosisi & $10(14.3 \%)$ \\
\hline Aceptable & $8(11.4 \%)$ \\
\hline Good & $52(74.3 \%)$ \\
\hline \multicolumn{2}{|l|}{ Reporto of pain } \\
\hline No & $50(71.4 \%)$ \\
\hline Yes & $20(28.6 \%)$ \\
\hline \multicolumn{2}{|c|}{ Drop in recente months } \\
\hline No & $53(75.7 \%)$ \\
\hline Yes & $17(24.3 \%)$ \\
\hline \multicolumn{2}{|l|}{ Fear of falls } \\
\hline No & $34(48.6 \%)$ \\
\hline Yes & $36(51.4 \%)$ \\
\hline \multicolumn{2}{|l|}{ Walking ai } \\
\hline No & $53(75.7 \%)$ \\
\hline Yes & $17(24.3 \%)$ \\
\hline
\end{tabular}

Table 3 shows the average of the questionnaires. The basic daily life activities (Katz) scale showed that 57 elderly people had the ability to perform basic activities of daily living independently, 5 were moderate dependent and 8 were dependent.

According to the MMSE evaluation, 25 elderly individuals presented moderate cognitive impairment, 27 mild cognitive impairment and 18 without cognitive impairment.

In relation to GDS, 37 elderly had a normal psychological presentation, 27 with mild depression and only 6 with severe depression.

Graph 1 shows a histogram which demonstrate the relationship between the 
Table 3. Avareage of questionnaries applied.

\begin{tabular}{lc}
\hline & $\mathrm{N}(\%)$ \\
\hline Katz & $57(81.43 \%)$ \\
Independents & $5(7.14 \%)$ \\
Moderate dependence & $8(11.43 \%)$ \\
High dependence & \\
MMSE & $18(25.71 \%)$ \\
Without commitiment & $27(38.57 \%)$ \\
Light commitiment & $25(35.71 \%)$ \\
Moderate commitiment & \\
GDS & $37(52.86 \%)$ \\
Normal psycological Picture & $27(38.57 \%)$ \\
Mild depression & $6(12.1 \%)$ \\
Severe depresion & \\
\hline
\end{tabular}

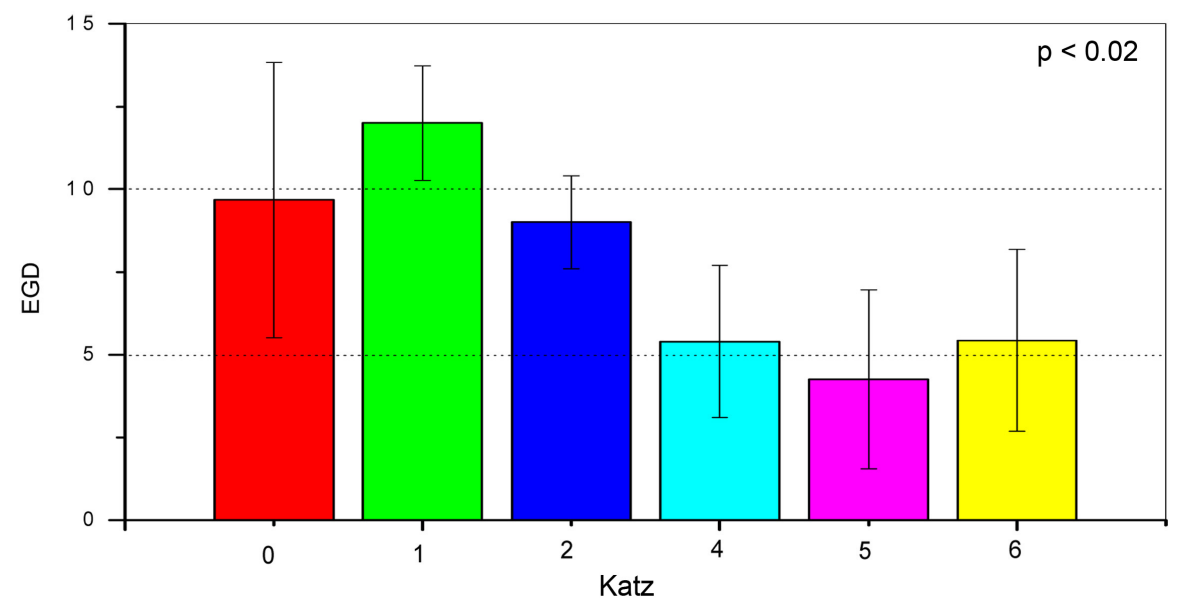

Graph 1. Relationship between the Katz index score and the GDS scale.

Katz index score and the GDS scale. We understand that the lower the Katz index, the higher the GDS, demonstrating a statistically significant relation $(\mathrm{p}<$ 0.02 ). This data suggests that individuals with lower functional level present a greater depressive presentation. This can be better understood in Graph 2.

Graph 2 shows a boxplot that demonstrates the same correlation of Graph 1 but is divided into two groups. The Katz score of $0-4$ represents a functional profile with total to moderate dependence and the other group, with a score of 5 to 6 , representing functional.

Independence. We can affirm through the analysis of this graph that, the elderly with a Katz index of 0 - 4, that is, a functional profile with total to moderate dependence, demonstrate a higher score in the GDS, with an average value of 9, showing a state moderate to severe depression. Moreover, the elderly with a Katz index of $5-6$, with functional independence, presented an average value of the geriatric depression scale of 5 , showing a significant correlation $(p<0.004)$ that there was no evident depressive state. 


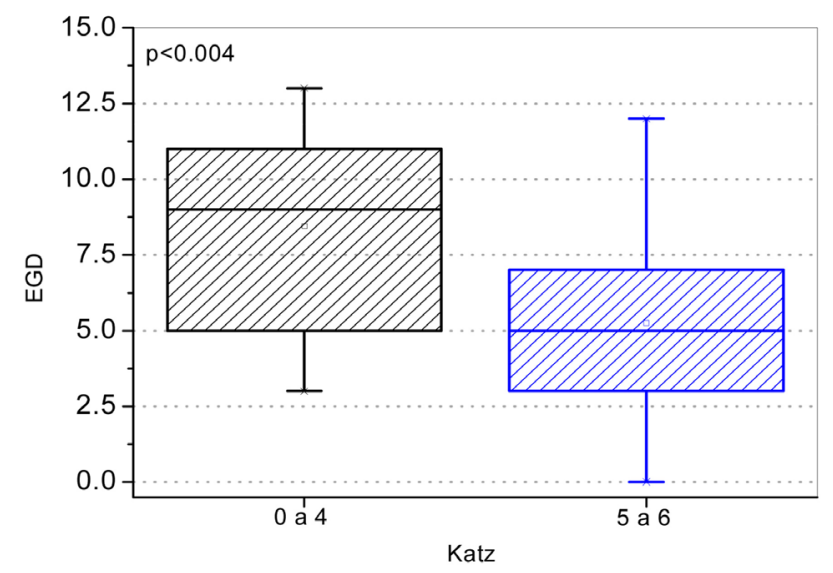

Graph 2. Box graph (boxplot) two level of Katz index with scale GDS.

Graph 1 shows a histogram which demonstrate the relationship between the Katz.

\section{Discussion}

According to the descriptive analysis presented, there is a predominance of the female gender $(57.1 \%)$, similar results were found in several studies, including one conducted in the northern brazilian coast of Brazil about the sociodemographic profile, family aspects, health perception, capacity functional and depression in the institutionalized elderly, in which $66.7 \%$ were females [14].

According to data from the IBGE in 2014, the life expectancy of women was 78.5 years and the men were 71.2 years. This may be one of the explanations of the greater prevalence of the female gender in HA, in addition to the population in general being composed, for the most part, of women $51.4 \%$ [15].

In relation to the marital status, it was verified that many of the institutionalized elderly are widowed, an equivalent response was verified in a study in HA of São Carlos (SP), in which $48 \%$ of the sample were widowers, a factor in consonance with our study, and which can be considered a reason for institutionalization [16]. It can also be verified in the present study that the majority of the elderly $65.7 \%$ had children, a result that diverges from studies done in HA of Bahia [17].

The average time of institutionalization was 55.1 months, ranging from 3 to 240 months. There were several reasons why the elderly took this decision, considering that $48.6 \%$ of hospitalizations were of their own volition, $34.3 \%$ were by family decision and $27.1 \%$ were homeless.

The study showed that a little more than half of the elderly $(54.0 \%)$ were visited, corroborating a study on the socioeconomic and epidemiological profile of institutionalized elderly in Brasília in which they presented similar results. About $51 \%$ of the elderly received visits from family members and acquaintances [18]. The visit to the institutionalized elderly person discharges the issue of abandonment and contributes to their adaptation to the new environment in which 
they will reside [16].

Some studies have demonstrated a large percentage of institutionalized elderly people with chronic diseases [18] [19], as well as the use of drugs [20], similar data can be observed in the present study in which $64.3 \%$ of the elderly said they had chronic diseases and $65.7 \%$ of medicines. The majority of participants reported good health $74.3 \%$ and only $14.3 \%$ said they considered bad health, the other $11.4 \%$ considered their health reasonable. Similar results can be observed in other studies [19].

The minority of the elderly interviewed reported chronic pain $28.6 \%$. These results corroborate the study done in the north coast of Rio Grande do Sul [21], in which only $13.3 \%$ of the elderly reported generalized pain. However, other studies show a high prevalence of chronic pain among institutionalized elderly people [22].

Such as one performed in Jequié (Bahia) 73.3\%. Pain research is fundamental to determine the measures necessary to promote the well-being and health of the elderly population [22].

The occurrence of falls in institutionalized people or not can have a major negative impact on their mobility, in addition to the risk of developing depression, the elderly may increase their anxiety and fear of falling again, increasing the risk of new occurrences [23].

The study found that only $24.3 \%$ of the elderly interviewed suffered falls in recent months. Similar data can be verified in another study [24], where the prevalence of falls was $37.2 \%$.

It can also be verified that in the present study, the group that suffered falls, the majority were female (70.59\%), being in accordance with a study carried out in the city of Catanduva (SP) [25], in which $71.4 \%$ of the elderly who suffered falls were women.

Despite the low number of elderly people who suffered falls in recent months (24.3\%), the study showed that just over half of the elderly are afraid of falling (51.4\%) and that of the group that was afraid, most were of the female gender $52.78 \%$. A study done in the city of Santos, SP was similar to the present study, with about $59.3 \%$ [26].

Regarding the dispositive to aid the gait, our study showed that only $25 \%$ of the elderly interviewed use some type of gait dispositive. Similar to the study done in Belo Horizonte (MG), where 38.3\% did not use a gait aid device [19]. Despite the percentage difference, it can be observed that the elderly who use some type of devices to aid gait are the minority (Table 2).

Our study found that the majority of the elderly $81.43 \%$ were independent for activities of daily living (ADL). A similar response can be observed in a study carried out in HA located in the city of João Pessoa, where it was observed that the majority of respondents $72.7 \%$ had good functional capacity to perform AVD [27]. In the evaluation of the ABVD in the elderly without cognitive decline, carried out in a survey in Belém do Pará, the vast majority were independent [28]. 
In relation to the depressive state of the institutionalized elderly, our study showed that $52.86 \%$ of the elderly did not present depressive symptoms, $38.57 \%$ presented mild depression and only $8.57 \%$ presented severe depression. This result is according to a study conducted in Curitiba [29], in which $55.54 \%$ of the elderly did not present depressive symptoms and $45.45 \%$ presented moderate to severe depression, with a mean of $4.68 \pm 3.29$, which is also in accordance with our study in which the average was $5.86 \pm 3.15$, values referring to a normal psychological presentation.

Another study carried out in the north of Rio Grande do Sul [30] showed that $57 \%$ of the elderly were classified as normal in GDS, 38\% had mild depression and $0.5 \%$ had severe depression. In the survey conducted in the federal district, $51 \%$ of the elderly interviewed had a normal psychological picture, $36.3 \%$ were classified as having mild depression and $12.7 \%$ were severely depressed. Thus, the investigations investigated, are in accordance with the data found in our research, stating that the majority of the institutionalized elderly do not present a depressive picture.

When we explore the relationship between GDS and the institutionalized elderly functionality evaluated through Katz, we can observe in that the higher the GDS score, the lower the Katz index. That is, the higher the level of depression, the greater the degree of dependence on the elderly. A study carried out in Maceió [31] showed that $65.0 \%$ of the institutionalized elderly have depressive symptoms and about $56.3 \%$ are dependent for the ABVD, confronting the present study in which the majority of the elderly were independent (81.43\%) and had a normal psychological picture (52.86\%).

However, it is possible to observe that the correlation between the two scales demonstrates that depressed elderly people are more susceptible to present a reduction in functional capacity. Such a result can also be observed in a review of depressive literature. This demonstrates that depression is associated with the functionality of the institutionalized elderly person.

During the research, we realized that the bedridden elderly people had the most restricted contact and the heads of the institutions limited the interviews with this group. New studies should be performed emphasizing the profile of these individuals, increasing the number of factors associated with depression in institutionalized elderly people, in which the low capacity or functional incapacity for pain was significantly associated with the symptoms of depression in the elderly of HA [32]. Elderly people with depression are more susceptible to demonstrate greater physical and emotional impairment, interfering with quality of life and consequently reducing functional independence [33].

\section{Conclusion}

The present study showed that there is a greater predominance of the female gender in HA, with an average of 74 years and with an average time of hospitalization of 55 months. The majority of the elderly were independent and a little 
more than half had a normal psychological picture. In the correlation of the variables depression and functionality, it was verified that the more functional the institutionalized elderly, the lower the chances of presenting the state of the bedridden elderly to verify if there is an increase in the prevalence of depressive elderly and if it is correlated with the functional capacity and autonomy.

\section{Acknowledgements}

To the elderly, their relatives, employees and responsible for long-stay institutions that helped and enabled this work to be carried out.

\section{Conflicts of Interest}

During the research, it was noticed that the bedridden elderly people had the most restricted contact, observing that the responsible ones of the institutions limited the realization of the interviews with the same ones.

\section{References}

[1] Silvério, J.K.A., Pedreira, K.M.A., Kutz, N.A. and Salgueiro, M.M.H.A.O. (2016) Nutritional Status of Institutionalized Elderly: A Literature Review. Academic Vision, 17, 3. https://doi.org/10.5380/acd.v17i3.49477

[2] Shumway-Cook, \& Woollacott (2013) Motor Control: Theoryand Practical Applications. Manole, São Paulo.

[3] De Oliveira, P.B. and dos Santos, D.M.T. (2014) Health Conditions of Elderly Residents in a Long Stay Institution According to Basic Human Needs. Revista Brasileira de Enfermagem, 67, 241-246. https://doi.org/10.5935/0034-7167.20140032

[4] Vaz, S.F.A. and Gaspar, N.M.S. (2018) Application of the Yesavage Geriatric Depression Scale in Long Permanence Institutions. Nursing Magazine, 21, 2030-2035.

[5] PAHO/WHO (2018) Depression. https://www.paho.org/pt/topicos/depressao

[6] Wannmacher, L. (2016) Approach to Major Depression in Theelderly: Measures Non-Medicated and Medicated. https://www.paho.org/bra/dmdocuments/Abordagem\%20idosos_F001.pdf

[7] Paraná (2014). Secretary of State for Health. Apsus Workshops: Elderly Health in Primary Care. SESA, Curitiba.

[8] Melo, R.L.P.., Eulálio, M.C., Silva, H.D.M., Silva Filho, J.M. and Gonzaga, P.S. (2013) Sense of Life, Functional Dependence and Quality of Life in the Elderly. Revista Brasileira de Geriatria e Gerontologia, 16, 230-250. https://doi.org/10.1590/S1809-98232013000200004

[9] Pinto, M.V.M. (2003) Enfoque da fisioterapia preventiva: Perfil dos idosos, asilamento e importância do apoio familiar em Caratinga MG. Fisioter Brasil, 5, 353-359. https://doi.org/10.33233/fb.v4i5.3050

[10] Porciúncula, R.C.R., Carvalho, E.F., Barreto, K.M.L. and Leite, V.M.M. (2014) Socioepidemiological Profile and Longevity Autonomy in Recife-PE, Northeast Brazil. Revista Brasileira de Geriatria e Gerontologia, 17, 315-325. https://doi.org/10.1590/S1809-98232014000200009

[11] Folstein, M.F., Folstein, S.E. and McHugh, P.R. (1975) "Mini-Mental State": A Practical Method for Grading the Cognitive State of Patients for the Clinician. Journal of 
Psychiatric Research, 12, 189-198.

https://doi.org/10.1016/0022-3956(75)90026-6

[12] Katz, S. and Chinn, A.B. (1959) Multidisciplinary Studies of Illness in Aged Persons: II. A New Classification of Functional Status in Activities of Daily Living. Journal of Chronical Diseases, 9, 55-62. https://doi.org/10.1016/0021-9681(59)90137-7

[13] Bertolucci, P.H.F., Brucki, S.M.D., Campacci, S.R. and Juliano, Y. (1994) O Mini-Examination of Mental State in a General Population. Impact of Schooling. Arquivos de Neuro-Psiquiatria, 52, 1-7. https://doi.org/10.1590/S0004-282X1994000100001

[14] Güths, J.F.S., Jacob, M.H.V.M., Santos, A.M.P.V., Arossi, G.A. and Béria J.U. (2017) Sociodemographic Profile, Family Aspects, Perception of Saúde, Functional Capacity and Depression in Institutionalized Elderly in the North Coast of Rio Grande do Sul, Brazil. Revista Brasileira de Geriatria e Gerontologia, 20, 175-185. https://doi.org/10.1590/1981-22562017020.160058

[15] Brazilian Statistics Institute (IBGE) (2014) Synthesisof social indicators: ananalysis of the living conditions of the Brazilian population: 2015/IBGE. Coordination of Population and Social Indicators.

https://biblioteca.ibge.gov.br/visualizacao/livros/liv95011.pdf

[16] Oliveira, S.C., Santos, A.A. and Pavarini, S.C.I. (2014) Relationship between Depressive Symptoms and the Family Functionality of Institutionalized Elderly. Revista da Escola de Enfermagem da USP, 48, 66-72. https://doi.org/10.1590/S0080-623420140000100008

[17] Lisbon, C.R. and Chianca, T.C.M. (2012) Epidemiological, Clinical and Functional Independence Profile of an Institutionalized Elderly Population. Revista Brasileira de Enfermagem, 65, 482-488.

[18] Oliveira, M.P.F. and Novaes, M.R.C.G. (2013) Socioeconomic, Epidemiological and Pharmacotherapeutic Profile of Institutionalized Elderly in Brasília, Brazil. Ciência \& Saúde Coletiva, 18, 1069-1078. https://doi.org/10.1590/S1413-81232013000400020

[19] Alencar, M.A., Bruck, N.N., Pereira, B.C., Câmara, T.M.M. and Almeida, R.D.S. (2012) Profile of the Elderly Living in a Long-Term Institution. Revista Brasileira de Geriatria e Gerontologia, 15, 785-796. https://doi.org/10.1590/S1809-98232012000400017

[20] Gonçalves, L.G., Vieira, S.T., Siqueira, F.V. and Hallal, P.C (2008) Prevalence of Falls in Retired Senior Citizens of the Municipality of Rio Grande, RS. Revista de Saúde Pública, 42, 938-945. https://doi.org/10.1590/S0034-89102008000500021

[21] Filipa, M.R.S. (2017) Functionality and Depressive Symptoms in People Aged 65+ Residing in the Community (Unpublished Master's Dissertation). Polytechnic Institute of Viana do Castelo.

[22] Tarakci, E., Zenginler, Y. and Kaya-Mutlu, E. (2015) Chronic Pain, Depression Symptoms and Daily Living Independency Level among Geriatrics in Nursing Home. AGRI, 27, 35-41. https://doi.org/10.5505/agri.2015.14238

[23] Brazil (2013) Ministry of Health. Fall Prevention Protocol: Protocol Elaborated by Proqualis Technical Team.

https://proqualis.net/sites/proqualis.net/files/Protocolo\%20-\%20Preven\%C3\%A7\% C3\%A3o\%20de\%20Quedas.pdf

[24] Ferreira, D.C.O. and Yoshitome, A.Y. (2010) Prevalence and Characteristics of Institutionalized Old Age Falls. Revista Brasileira de Enfermagem, 63, 991-997. https://doi.org/10.1590/S0034-71672010000600019 
[25] Lojudice, D.C., Laprega, M.R., Rodrigues, R.A.P. and Rodrigues Jr., A.L. (2010) Institutionalized Elderly Falls: Occurrence and Associated Factors. Revista Brasileira de Geriatria e Gerontologia, 13, 403-412. https://doi.org/10.1590/S1809-98232010000300007

[26] Uchida, J.E.F. and Borges, S.DE M. (2013) Falls in Institutionalized Elderly. Revista Kairós Gerontologia, 16, 83-94.

[27] Duarte, M.C.S., Ubiraciara, L., Soares; Albuquerque, K.F., Evangelista, C.B., Souto, H.C. and Patrício, A.C.F.A. (2015) Fragilidade e status funcional de idosos institucionalizados. Revista de Pesquisa: Cuidado é Fundamental Online, 7, 2688-2696. https://doi.org/10.9789/2175-5361.2015.v7i3.2688-2696

[28] Silva, J.K.S., Albuquerque, M.C.S., Souza, E.M.S., Silva Monteiro, F.Y. and Esteve, G.G.L. (2015) Depressive Symptoms and Functional Capacity in Institutionalized Elderly People. Culture of Care (Digital Edition), 19, 41.

[29] Trindade, A.P.N.T., Barboza, M.A., Oliveira, F.B. and Borges, A.P.O. (2013) Repercussion of Cognitive Decline in Functional Capacity in Institutionalized and Non-Institutionalized Elderly. Fisioterapia em Movimento, 26, 281-289. https://www.scielo.br/revistas/fm/iaboutj.htm

[30] Raldi, G.Y., Cantele, A.B. and Palmeiras, G.B. (2016) Evaluation of the Prevalence of Depression in Institutionalized Elderly People in an LSIE in the North of Brazil. Revista de Enfermagem, 12, 48-63.

[31] Silva, T.B.V., Magalhães, C.M.C. and Abreu, D.C.C. (2015) Functional Capacity of Elderly People in Institutions of Long Stay of the Public Network in a Capital of the Northern Region. Estudos Interdisciplinares sobre o Envelhecimento, 20, 2, 517-534. https://seer.ufrgs.br/RevEnvelhecer

[32] Nóbrega, I.R., Alves, P., Leal, M.C.C., Marques, A.P.O. and Vieira, J.C.M. (2015). Factors Associated with Depression in Institutionalized Elderly: An Integrative Review. Saúde em Debate, 39, 536-550. https://doi.org/10.1590/0103-110420151050002020

[33] Santos, J.G. (2012) Depressive Symptoms and Functional Impairment of the Elderly in a Geriatric Day Central. Jornal Brasileiro de Psiquiatria, 61, 102-106. 